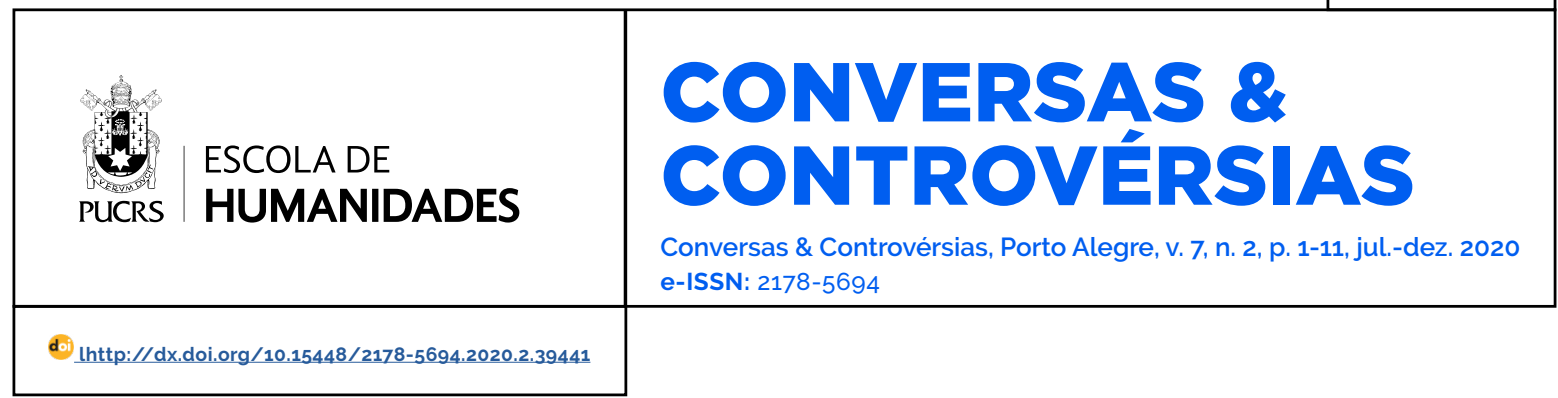

DOSSIÊ - INSTITUIÇÕES E PRÁTICAS ECONÔMICAS EM FOCO: CONTRIBUIÇÕES DAS CIÊNCIAS SOCIAIS

\title{
Conectando intimidade e economia através das obras de Viviana Zelizer
}

\author{
Connecting intimacy and economy through the ideas of Viviana Zelizer \\ Conectando intimidad y economia a través de las obras de Viviana Zelizer
}

\section{Renata Bezerra \\ Milanês ${ }^{1}$ \\ orcid.org/0000-0003-1140-3684 renatamilanes@hotmail.com}

Recebido em: 28/10/2020. Aprovado em: 19/02/2021 Publicado em: 08 jun. 2021.

\section{(c) (i)}

Artigo está licenciado sob forma de uma licença Creative Commons Atribuição 4.0 Internacional.
Resumo: O presente artigo tem como objetivo oferecer uma sintese do pensamento da socióloga argentina Viviana Zelizer e das suas contribuições sobre o significado cultural e moral da economia. Através de um diálogo com suas obras, o texto trazido aqui, busca demonstrar como as relações econômicas são constantemente moldadas pelos sistemas de significados atribuidos pelas pessoas e pelos contatos sociais que elas estabelecem no intercurso da vida cotidiana. O artigo busca demonstrar como as relações intimas e os afetos se conectam com as transações econômicas. Para tanto, a autora nos oferece uma contraposição ao esquema teórico convencional da economia clássica e neoclássica, segundo o qual o mercado afeta de maneira altamente prejudicial a solidariedade e as relações pessoais. Dessa forma, ao superar a oposição entre intimidade e economia, a análise dos mundos conectados de Zelizer nos oferece uma alternativa para pensar sobre a dinâmica da vida social, não apenas pelo viés das instituições, das organizações, dos valores e da racionalidade, mas também a partir do enraizamento e da relação com os aspectos sociais, culturais e afetivos que permeiam a vida dos indivíduos.

Palavras-chave: Viviana Zelizer. Nova sociologia econômica. Mundos conectados.

Abstract: This article aims to offer a presentation of the theoretical line of Argentine sociologist Viviana Zelizer and her contributions to the cultural and moral significance of the economy. Dialoguing with her works, the text brought here seeks to demonstrate how economic relations are constantly shaped by the systems of meanings attributed by people and by the social contacts they establish in the intercourse of daily life. The article seeks to demonstrate how intimate relationships and affections are connected with economic transactions. To this end, the author offers us a contrast to the conventional theoretical scheme of classical and neoclassical economics, according to which, the market affects solidarity and personal relationships in a highly damaging way. Thus, when overcoming the opposition between intimacy and economy, Zelizer's analysis of connected worlds offers us an alternative to think about the dynamics of social life, not only through the bias of institutions, organizations, values, and rationality but yes, based on its roots and its relationship with the social, cultural and affective aspects that permeate the lives of individuals.

Keywords: Viviana Zelizer. New economic sociology. Connected lives.

Resumen: En este artículo se objetiva ofrecer una sintesis del pensamiento de la socióloga argentina Viviana Zelizer y sus aportes sobre el significado cultural y moral de la economía. Por medio de un análisis de las obras de la autora, este texto busca demostrar cómo las relaciones económicas son moldeadas constantemente por los sistemas de significados atribuidos por las personas y por los contactos sociales que son establecidos en las relaciones de la vida cotidiana. Este artículo busca demostrar cómo las relaciones intimas y los afectos están conectados a las transacciones económicas. Para ello, la autora nos ofrece un contraste con el esquema teórico convencional de la economía clásica y neoclásica, según el cual el mercado afecta la solidaridad y las relaciones personales de 
manera altamente dañina. Así, al superar la oposición entre intimidad y economía, el análisis de Zelizer de los mundos conectados nos ofrece una alternativa para pensar en la dinámica de la vida social, no sólo a través del sesgo de las instituciones, organizaciones, valores y racionalidad, pero también basado en las raices y la relación con los aspectos sociales, culturales y afectivos que permean la vida de los individuos.

Palabras clave: Viviana Zelizer. Nueva sociología económica. Mundos conectados.

\section{Introdução}

O presente artigo tem como objetivo oferecer uma sintese da linha teórica percorrida pela socióloga argentina Viviana Zelizer e de suas contribuições sobre o significado cultural e moral da economia. Através de um diálogo com as obras da autora, o texto trazido aqui busca demonstrar como as relações econômicas são constantemente moldadas pelos sistemas de significados atribuidos pelas pessoas e pelos contatos sociais que elas estabelecem no intercurso da vida cotidiana. Ao superar as dualidades puristas e ao oferecer uma contraposição ao esquema teórico convencional da economia clássica e neoclássica, segundo o qual as transações mercantis afetam de maneira altamente prejudicial a solidariedade e as relações pessoais, a autora busca demonstrar como as relações intimas e os afetos se conectam com as transações econômicas. Dessa forma, ao superar a oposição entre intimidade e economia, a análise dos mundos conectados de Zelizer nos oferece uma alternativa para pensar sobre a dinâmica da vida social, não apenas pelo viés das instituições, das organizações, dos valores e da racionalidade, mas também a partir do enraizamento e da relação com os aspectos sociais, culturais e afetivos que permeiam a vida dos individuos.

Por um longo periodo, tem se destacado no campo das Ciências Sociais as abordagens sobre os efeitos patológicos do mercado, que apontam com total convicção, o fato de que o capitalismo e o século 21 têm trazido mudanças danosas para a vida das pessoas em sociedade. De acordo com Freire (2014), nas teorias clássicas, o mercado e a vida econômica, em geral, além de serem considerados como nefastos, são vistos como capazes de "erodir, sufocar e corromper os laços, valores e qualidades não-mercantis, os quais, segundo o seu juizo, são imprescindiveis para a existência de uma sociedade mais justa e de uma individualidade plena" (Freire 2014, 259).

Zelizer (2005b) afirma que durante 200 anos os teóricos sociais têm se preocupado muito com a incompatibilidade, a incomensurabilidade ou a contradição entre as relações de intimidade e as relações impessoais, pois, desde o século 19, os analistas sociais assumiram que o mundo social se organiza em torno de principios incompativeis, tais como: atribuição e realização, sentimento e racionalidade, solidariedade e interesse próprio. Diante dessa visão, o mercado e a vida econômica estariam, então, sufocando, destruindo e contaminando os laços, os valores e as qualidades não-mercantis da sociedade. Por essa razão, com a mercantilização cada vez mais imponente da vida social, a essência das relações e dos vinculos pessoais tenderia a ser suprimida, anulada e ameaçada de desaparecer.

Essa forma de compreensão da realidade ocorre porque, de acordo com Zelizer (2009), os economistas têm, ao longo do tempo, dicotomizado o mundo em mercado e não-mercado; racional e pessoal; eficiente e sentimental; macho e fêmea. Partindo desse ponto de vista reducionista, as atividades econômicas degradariam. Portanto, as relações intimas e a intimidade interpessoal tornariam a atividade econômica ineficiente. No entanto, essas dicotomias, por sua vez, têm sido mais enganadoras do que úteis para a análise social, pois, como bem ressalta Zelizer (2009), a vida econômica e o comportamento organizacional têm encontrado caminhos para a criação de relações que vão muito além dessas fronteiras e que não necessariamente "destroem" ou "corrompem" a integridade da vida social, como pressupunham os economistas clássicos, mas se misturam regularmente e também se reforçam e se complementam mutuamente.

Zelizer (2005a), por sua vez, afirma que acredita, sim, que o século 21 trouxe consigo consequências para a humanidade e para a vida em sociedade, mas a autora pondera que essas mudanças não decorrem exclusivamente pelo fato de que a mer- 
cantilização da vida esteja aniquilando para sempre a intimidade. Por essa razão, ao invés de seguir com uma postura apocalíptica, ela se propõe a sair de uma perspectiva maniqueísta e reducionista de análise para buscar apreender como as relações intimas e os afetos se conectam com as transações econômicas e comerciais, observando, assim, como ocorrem as interações entre mercados, transações e relações pessoais nos dias atuais.

Partindo de uma nova forma de encarar essas questões, Ertman (2009) aponta que Zelizer transcende a tendência comum de tratar as esferas de mercado e não-mercado, a partir de uma perspectiva simplista, como se fossem: "hostile worlds (à la Michael Walzer) or nothing but another monolithic system (à la Chicago school legal economics)" (Ertman 2009, 1018). Segundo essa autora, Zelizer cataloga os defensores das abordagens "nothing but" em três campos principais: "nothing but economic rationality, nothing but culture, and nothing but politics" (Ertman 2009, 1022).

Convém frisar, como bem pontua Freire (2014), que a vida emocional e as relações pessoais, até os dias atuais, ainda são subestimadas dentro das análises econômicas e sociológicas. Isso faz com que a dicotomia entre emoções e racionalidade tenha uma vigorosa persistência e consolide um papel estruturante, tanto na delimitação dos fenômenos empíricos quanto do domínio do pensamento sociológico. De acordo com o autor, muito mais do que dicotomias ou polarizações abstratas: "podemos identificar nos estudos da vida econômica capitalista uma visão valorativa e moral com respeito às relações dos fatos econômicos com os afetos e com a vida emocional dos individuos" (Freire 2014, 258).

Todavia, segundo Zelizer (2008), a Sociologia Econômica tem mudado bastante nas últimas décadas, sobretudo por questionar as correntes dominantes da economia e propor a construção de explicações alternativas para a compreensão das atividades econômicas. Configuração essa que, de acordo com a autora argentina, acabou por aproximar os sociólogos econômicos, tanto de produções inovadoras na ciência econômica, como de abordagens analíticas mais contemporâneas.
Enquanto os pensadores econômicos clássicos tendem a dividir o mundo em esferas separadas (ou "mundos hostis") e mutuamente contaminantes, onde, de um lado estariam as transações racionais de mercado, e do outro as relações sociais pessoais, ou intimas; os pensadores da corrente da Nova Sociologia Econômica (NSE), dentre os quais se enquadra a abordagem de Zelizer, acreditam que essas dicotomias distorcem a compreensão de como a atividade econômica de fato opera, pois acabam servindo para desvalorizar atividades, como a produção doméstica, o trabalho do cuidado e o trabalho das mulheres.

Zelizer define que a teoria das esferas separadas se baseia no pressuposto de que "la actividad económica racional y las relaciones personales constituyen arenas diferentes, una de cálculo y eficiencia, la otra de sentimientos y solidaridad" (Zelizer 2008, 99). A autora complementa dizendo que a doutrina dos mundos hostis sustenta que: "el contacto entre ambas esferas resulta en contaminación y desorden: la racionalidad económica corrompe la intimidad, y las relaciones intimas obstaculizan la eficiência" (Zelizer 2008, 99). Para ela, a abordagem das esferas separadas e dos mundos hostis, ao invés de reconhecer que o funcionamento do mercado depende de uma rede de relações interpessoais que são negociados cotidianamente, acaba preservando a crença de que as atividades econômicas seriam protagonistas das ações, obedecendo leis próprias, e as relações sociais atuariam apenas como coadjuvantes nesse processo.

Todos esses argumentos podem nos levar a refletir sobre alguns questionamentos principais que perpassam as obras da autora, tais como: por que as pessoas se preocupam tanto com a mistura entre a intimidade e o econômico? Será que a intimidade é tão frágil assim, a ponto de poder deixar de existir, se entrar em contato com o dinheiro ou com interesses econômicos? Ao invés de achar que a manutenção das relações intimase a condução da atividade econômica são domínios incompativeis, não seria mais interessante pensar em como as pessoas gerenciam essas duas esferas? Ou ainda, em que condições e quais são 
as diferentes situações em que se misturam as transações econômicas e a intimidade? Como é possivel analisar determinados contextos íntimos atravessados por pagamentos e usos de dinheiro, sem cair em interpretações dicotômicas?

Levando em conta essas questões, espera-se que este artigo possa servir como um guia para aqueles que pretendem se aventurar no fazer sociológico proposto por Zelizer, que nos ensina a misturar economia e intimidade como uma forma de explorar novos entendimentos sobre o funcionamento da vida social e, a partir das suas contribuições teóricas, lançar novas questões para se pensar sobre as abordagens criticas e contemporâneas no campo da Sociologia Econômica.

\section{Viviana Zelizer e o significado cultural e moral da economia}

Viviana A. Rotman Zelizer é socióloga e professora de Sociologia na Universidade de Princenton. Nascida em 1946, estudou Direito na Argentina por dois anos, na Universidade de Buenos Aires. Em 1967, imigrou para os Estados Unidos e, em 1974, se formou na Universidade de Rutgers. Fez pós-graduação em Sociologia na Universidade de Columbia e, em 1977, obteve o título de Ph.D. Zelizer (2020) aponta quatro estudiosos da Universidade de Columbia que influenciaram, de maneira marcante, na sua trajetória de formação intelectual, são eles: Sigmund Diamond, Bernard Barber, Georg Simmel, David Rothman e Robert K. Merton.

Até o momento, as principais obras publicadas da autora são: Morals and markets: the development of life insurance in the United States (1979); Pricing the priceless child: the changing social value of children (1985); The social meaning of Money (1994); The purchase of intimacy (2005b); Economic lives: how culture shapes the economy (2010); seu livro mais recente é Money Talks: Explaining How Money Really Works (2017).

No que diz respeito à forma de trabalhar da autora, Zelizer (2007) assume que a abordagem tende, primeiro, a destacar um problema descritivo e explicativo e, a partir daí, ela busca autores que contribuíram para a análise desse problema. O que a interessa é muito mais a maneira de pen- sar desses autores, do que a busca de teóricos especificos para embasar pesquisas.

Em uma entrevista concedida a pesquisadores brasileiros, Zelizer disse que trabalhar a partir de um conjunto de materiais empíricos dos Estados Unidos da América, acabou fazendo com que ela levantasse questões mais gerais sobre as formas como o dinheiro funciona. Contou, também, que sua "obsessão pelo dinheiro", ou, mais especificamente, pelos sentidos sociais do dinheiro enquanto tema de análise, começou com a preocupação que ela tinha a respeito "dos modos de atribuir valor às vidas humanas, antes que com uma preocupação teórica quanto à natureza do dinheiro" (Guimarães et al 2017, 192).

Em outra entrevista, ao ser questionada sobre como se envolveu com a sociologia econômica, Zelizer (2007,41) respondeu que, na verdade, se considerava uma "historical sociologist", mas não no sentido de comparar grandes regimes econômicos, impérios ou revoluções industriais. A autora aponta, que, quando escreveu sua tese de doutorado, transformada no livro Morals and Markets, não tinha a mínima ideia de que estava contribuindo para a sociologia econômica (Ossandón e Zelizer, 2019).

A autora também considera sua obra The purchase of intimacy (2005) um trabalho de história social, feito através da análise de documentos históricos e de investigações, com foco nos conflitos sociais. Porém, segundo ela, estudiosos que pertenciam à sociologia econômica, tais como Pierre Bourdieu, Harrison White e Richard Swedberg, começaram a utilizar e referenciar o seu trabalho e a tratá-lo como um desafio ao pensamento econômico convencional, e isso acabou posicionando-a entre as discussões de uma "nova" sociologia econômica.

Nessa mesma entrevista (Ossandón e Zelizer, 2019), a socióloga revelou que sua contribuição para a sociologia econômica foi acontecendo aos poucos, pois o que fazia até então, era considerado como periférico, não só no que diz respeito aos métodos do seu trabalho, mas também em relação aos temas de suas investigações. Com relação a este último ponto, ela afirmou, de ma- 
neira incisiva, que o foco dos seus estudos era as relações e conexões sociais, e complementou: "my agenda is to dispute simplistic causal assumptions" (Ossandón e Zelizer 2019, 195).

Em sua página pessoal, ${ }^{2}$ no site da Universidade de Princeton, Zelizer aponta que, em geral, seu trabalho envolve situações nas quais a relação entre a atividade econômica e a vida pessoal estão sempre mudando. Um grande exemplo dessas transformações é abordado em seu primeiro livro Morals and markets: the development of life insurance in the United States (2017): um estudo pioneiro sobre o seguro de vida nos Estados Unidos, em que Zelizer observa como, ao longo do tempo, os americanos deixaram de estigmatizar esse produto-fenômeno, condenando-o moralmente, por ele ser uma forma de precificar a vida, e passaram a aceitá-lo, vendo-o como uma garantia importante para o futuro das familias.

Zelizer ${ }^{3}$ demonstra que as pessoas gostam de pensar, tanto no dinheiro como na intimidade, como constituindo dois domínios separados, e que isso faz com que surja a preocupação recorrente de que o dinheiro pode transformar a vida privada dos indivíduos em um mercado monetizado. Porém, em suas obras, a autora desafia essa visão e demonstra que, ao invés de corromper a intimidade, as pessoas utilizam as ações econômicas e o dinheiro para criar, manter e renegociar importantes laços íntimos, sem necessariamente danificá-los. Segundo Ossandón (2019), ao contrário das suposições da economia neoclássica de que as pessoas seguem uma lógica calculista e individualista em todas as relações classificadas como econômicas, as ideias de Zelizer demonstram que o dinheiro desempenha um papel fundamental na configuração e demarcação das relações sociais, assim como das regras e obrigações.

De acordo com Wilkinson (2016), o trabalho de Zelizer é focado na forma como os valores condicionam e permeiam a atividade econômica. Sendo assim, a autora tem demonstrado, através de suas pesquisas, como os mercados são conformados por convicções e práticas sociais e culturais. Dessa forma, partindo de uma perspectiva que enfoca a atribuição do significado cultural e moral às práticas econômicas da economia, Zelizer demonstra que, ao invés de se chocarem, se ferirem e se contaminarem, economia e laços sociais se sustentam mutuamente e se complementam.

Freire (2014) define a abordagem de Zelizer como sendo sociológica, não reducionista e não dicotômica "dos vínculos entre intimidade, cultura e economia, de sorte a suscitar uma perspectiva crítica e questionadora das visões convencionais e fatalistas que antagonizam mercado e vida emocional dos individuos" (Freire 2014, 260). Ossandón (2019) complementa esse raciocínio, pontuando que o trabalho da socióloga argentina não é apenas um contrapeso no que se considera a NSE, mas oferece um ângulo original e distinto para o estudo da vida econômica.

Em A economia do care, Zelizer (2010) explicita que, durante os últimos 25 anos, tanto nos Estados Unidos da América quanto na Europa, a Sociologia Econômica deixou de focalizar as análises exclusivamente nas firmas, nos mercados e na teorização pela Ciência Econômica, para se abrir a perspectivas mais amplas e diversas. Segundo a autora, é importante destacar essa questão, pois, durante muito tempo, os cientistas econômicos negligenciaram o contexto cultural e social das análises. Também ignoraram atividades como a do care como interesse de pesquisa, justamente por se tratar de um trabalho exercido em grande medida por mulheres, no âmbito da intimidade e por evolver, necessariamente, o estabelecimento de vínculos e afetos. Nesse sentido, o fato do tema do care ter se tornado um objeto de estudo revela a necessidade de transformações e renovações nesse campo da disciplina.

A emergência de uma NSE, segundo Freire (2014), começa a despontar nos Estados Unidos no início dos anos 80 , recuperando um antigo

Princeton University. 2002. Viviana A. Zelizer. Departament of Sociology. Acessado em 20 jul. 2020. https://sociology.princeton.edu/ people/viviana-zelizer

Princeton University. 2002. Viviana A. Zelizer. Departament of Sociology. Acessado em 20 jul. 2020. https://sociology.princeton.edu/ people/viviana-zelizer 
debate entre Sociologia e Economia, colocando em questão a ideia de que os fatos econômicos poderiam ser explicados unicamente pelo viés das motivações, oriundas de um suposto comportamento racional e universal dos atores, movidos única e exclusivamente pela maximização de interesses particulares.

Steiner (2006) observa que a NSE começa a entrar em cena diante de um contexto de descontentamento a respeito dos pressupostos tradicionais da Economia e da Sociologia, buscando formular explicações, alternativas e abordagens críticas. Lopes Júnior (2002) afirma que, de um lado, a NSE procura criar novas formas de explicar os processos econômicos e, do outro, intenta reagir de maneira mais contundente contra o "imperialismo disciplinar da Economia ocorrida na década de 80" (Lopes Junior 2002, 39).

Portanto, diferente do que vinha sendo considerado até então, para a NSE, nem as leis abstratas (descoladas do mundo social que regem as transações), nem a racionalidade instrumental do ator, dariam conta de explicar a complexidade de fatores e motivações não-econômicas que estão presentes na ação econômica e no comportamento dos indivíduos (Freire 2014). A crítica principal proposta pela NSE, segundo Freire (2014), dirige-se à tese segundo a qual a economia seria uma esfera autônoma e independente da vida social. Essa postura implica em considerar que os pesquisadores não aceitam mais enxergar os atores como agentes passivos ou como "meros suportes das estruturas sociais, ou de vitimas das forças econômicas arrasadoras" (Freire 2014, 272). Dessa forma, as relações humanas não estão subordinadas à racionalidade dos interesses ou das escolhas individuais, tal como pressupõe a análise econômica convencional, mas "implicam emoções, a negociação do status das relações interpessoais, os códigos culturais compartilhados, intimidade, dilemas éticos, identidade" (Freire 2014, 282).

As novas abordagens dentro desse campo visam demonstrar, portanto, a inadequação e a limitação dos esquemas teóricos que sustentam a ideia de um homo economicus que age naturalmente, pautado por uma racionalidade, que leva em consideração apenas o seu ganho e o seu auto interesse. Além disso, também visam por em xeque as crenças de que o econômico, por meio do dinheiro e do mercado, corrompe a intimidade e a autenticidade das relações pessoais

Lopes Júnior aponta que, na década de 9o, atualizando de forma crítica as ideias propostas por Polanyi, de separação do econômico em relação às demais esferas da vida social (Polanyi 1949, apud Lopes Júnior 2002), as pesquisas da NSE criam "um excitante novo movimento teórico na Sociologia" (Lopes Júnior 2002, 41), incorporando perspectivas analíticas paralelas, tais como a análise de rede, os estudos culturais e o neo-institucionalismo, que permitiram uma maior sofisticação das abordagens sobre a vida econômica.

$\mathrm{Na}$ década de 1980, em um dos textos que consolida o surgimento do campo da NSE, Granovetter (2007) reformulou o conceito de embeddedness, de Polanyi, ao pontuar que a ação econômica também é uma forma de ação social, ou seja, as relações mercantis perpassam e são perpassadas o tempo todo pelas relações sociais. Dessa maneira, tal como sugere Granovetter (2007), as relações sociais, mais do que dispositivos institucionais ou de moralidade generalizada, são também as principais responsáveis pela produção de confiança na vida econômica.

Segundo Granovetter (2005), as redes de relações sociais são formadas por laços fortes ou fracos entre os individuos. Os do primeiro tipo são formados por contatos frequentes e de longa duração, que acionam recursos, como solidariedade, confiança e ajuda mútua. Já os laços do segundo tipo são os relacionamentos menos constantes e de curta duração. Vale e Guimarães (2010, 327) corroboram essa diferenciação, dizendo: "enquanto vínculos fortes sugerem redes (comunidades ou conjuntos) coesas e interconectadas, vínculos fracos sugerem contatos e relacionamentos eventuais e superficiais, que se estabelecem entre diferentes redes".

De acordo com Granovetter (2005), os contatos pessoais, o fluxo de informações, as relações de confiança e reciprocidade e outros mecanismos informais são fatores decisivos de interação no 
interior da ordem econômica. Essa abordagem questiona os postulados da teoria econômica hegemônica, segundo a qual o mercado se estruturaria pela mera interação de individuos independentes uns dos outros, interação esta fundada tão-somente em escolhas racionais de caráter formal. Porém, para Granovetter (2005), os individuos não são pessoas isoladas e os laços sociais influenciam as trajetórias. Além do mais, as iniciativas e oportunidades das quais dispõem são influenciadas pela natureza das redes nas quais se inserem. Portanto, a compreensão do funcionamento da ordem econômica supõe levar em consideração as interações sociais, num sentido mais abrangente.

Seguindo a linha traçada por Polanyi e, posteriormente, por Granovetter, Lopes Júnior (2002) considera que uma das primeiras aplicações dos princípios teórico-metodológicos, que passariam a configurar a NSE, desponta com o trabalho de Zelizer a respeito da construção social do mercado de seguros nos EUA. Para o autor, a pesquisa de Zelizer é uma referência fundamental na análise da construção social dos mercados, "constituindo-se numa contraposição empiricamente apoiada da ideia de autonomização do mercado perante a vida social" (Lopes Junior 2002, 40).

Na contramão de uma perspectiva fragmentada da vida social, para Zelizer (2008), o desafio do entendimento dos processos econômicos não se restringe apenas à Sociologia Econômica, pois as mudanças que afetaram esse campo do conhecimento também fazem parte das transformações que ocorreram em outras áreas. A autora destaca, por exemplo, que correntes, como a economia comportamental, a economia feminista, a economia organizacional, a economia institucional e, mais recentemente, a neuroeconomia, questionaram e puseram em evidência várias críticas aos modelos neoclássicos da economia, oferecendo interpretações inovadoras das atividades econômicas, a partir de análises que incluiam visões mais sociais e culturais sobre os mercados (Zelizer 2008). Essas novas lentes de análise deram suporte para o surgimento de explicações alternativas sobre os processos econômicos, incorporando o papel relevante das redes de relacionamentos interpessoais, para os quais a socióloga argentina dirigiu suas pesquisas por muitos anos.

\section{Conectando intimidade e economia através das obras de Viviana Zelizer}

Em seu artigo Dualidades perigosas, Zelizer (2009) aponta que as teorias duais ganharam força nos debates acadêmicos como uma forma de reação ao capitalismo industrial do século 19, pois tanto os defensores quanto os críticos do capitalismo industrial adotaram a premissa de que a racionalidade industrial estaria acabando com a solidariedade, o sentimento e a intimidade dos mercados, das empresas e das economias nacionais.

Partindo desses pressupostos, Zelizer (2005. 2009) refuta basicamente dois estilos de análise: a teoria das esferas separadas e a dos mundos hostis. A primeira diz que há dois dominios distintos que operam segundo diferentes principios: racionalidade, eficiência e planejamento, de um lado, e solidariedade, sentimento e impulso do outro. A segunda pressupõe que, quando tais esferas entram em contato, contaminam e desordenam umas às outras. Na visão dos mundos hostis, a esfera dos sentimentos e da solidariedade é incompativel com a esfera do cálculo e da eficiência, pois, se, por um lado, a existência de sentimentos dentro da esfera econômica é interpretada como algo que gera ineficiência, corrupção e favoritismo nos negócios, do outro, a racionalidade na esfera sentimental é culpada por destruir a solidariedade.

Zelizer (2009) nos ajuda a entender essa questão, apontando que os diferentes dominios da realidade se revelam imbricados e emaranhados uns nos outros. Nesse sentido, a esfera do trabalho e do econômico não são "hostis" à esfera da familia, à doméstica e da afetividade. Essa configuração denota a ideia de que as estratégias que os indivíduos assumem no contexto do qual fazem parte não são estritamente econômicas, mas englobam outras de valor.

As doutrinas dos mundos hostis estão vivas e continuam a tratar do mix intimidade versus tran- 
sações econômicas como uma anomalia perigosa e, por isso, pregam que se deve isolar as relações domésticas, os cuidados pessoais e o amor de um mundo invasor, predatório, econômico. Essas preocupações acerca da incompatibilidade entre mercado e relações íntimas e sobre a invasão do mundo sentimental pela racionalidade instrumental têm como pressuposto que a mistura das duas esferas gera uma ineficiência nas transações e que "only markets cleansed of sentiment can generate true efficiency" (Zelizer 2005, 24).

Nessas perspectivas é bastante recorrente a ideia de uma "contaminação moral", que vê como um fator de risco a mistura do econômico com a intimidade e, por isso, os analistas dessas correntes defendem a necessidade da separação das duas esferas, com o intuito de manter fronteiras bem delimitadas entre o mercado e os dominios intimos. Discordando dessa prerrogativa, Zelizer coloca que, ao invés de manter os dois domínios distantes uns do outro, é mais interessante reconhecer que todo mercado depende de relações interpessoais, pois os fenômenos monetários dependem de práticas sociais que são continuamente negociadas. Portanto, a socióloga argentina abandona os argumentos das esferas separadas e dos mundos hostis, em detrimento de uma abordagem que enfoque os laços sociais, diferenciados, com seus respectivos sistemas de contabilidade, meios, transações econômicas, significados e delimitações particulares.

Fernandes (2013) atenta para o fato de que a abordagem proposta por Zelizer nos permite destrinchar as condições pelas quais as pessoas organizam seus sentimentos, em conjunto com as práticas econômicas e, mais especificamente, como lidam com os fluxos de pagamentos e dinheiro. Porém, como adverte o autor, "não se trata apenas da inserção do dinheiro nas relações intimas, mas antes da forma como ele é usado, do meio de negociação e do sentido e da propriedade atribuidos a este agente" (Fernandes 2013, 401).

Freire (2014) também considera que a obra de Zelizer nos coloca diante de uma sociologia que se preocupa com aspectos culturais, valores sociais e elementos afetivos na dinâmica e estruturação dos mercados, pois "o estabelecimento de valores mercantis e monetários a bens considerados culturalmente inalienáveis mobilizam e colidem, irremediavelmente, com os códigos de moralidade e de sentimentos dos indivíduos" (Freire 2014, 266).

Nas próprias palavras de Zelizer (2010), o que mais importa não é perguntar se o dinheiro corrompe ou não as relações sociais, mas, sim, analisar as combinações entre os diferentes domínios e observar o que pode surgir de interessante, pois, segundo a autora, "não é a combinação em si mesma que deve nos interessar, mas o modo como ela funciona. Se identificarmos mal as conexões causais ocultaremos a origem das injustiças, dos danos e dos perigos" (Zelizer 2010, 386). Lopes Júnior (2002) afirma que uma das grandes contribuições teóricas das investigações desenvolvidas por Zelizer consiste justamente em demonstrar que "as moedas também se movem nas relações aparentemente mais distanciadas da lógica mercantil, dentre elas os relacionamentos pessoais" (Lopes Junior 2002, 55).

Outro aspecto relevante, fruto do trabalho de Zelizer (2005b), se encontra no livro The purchase of intimacy. Nele, a autora defende a ideia de que a vida em sociedade exige a constante negociação dos limites, além de combinações entre transações econômicas e relações pessoais. Para isso, ela nos oferece o conceito de relational work ou "trabalho relacional", que diz respeito ao trabalho envolvido nas relações intimas, que requer a distinção meticulosa entre as diferentes relações possiveis.

Nessa obra, Zelizer (2005b) observa como, nos Estados Unidos, tanto as práticas cotidianas como as leis regulam a interseção das relações pessoais intimas com a atividade econômica. Para tanto, a autora defende a ideia de que as pessoas criam vidas conectadas e que vão diferenciando seus múltiplos laços sociais, marcando limites e negociando o conteúdo entre os diferentes vínculos, que se dão através da prática, das atividades econômicas.

Para Zelizer (2007), os padrões, as hierarquias econômicas, os conceitos de rede e de mercado não são capazes de capturar a forma organizacional das conexões econômicas, o que faz com que a autora afirme: "I see those connections as 
organizing into circuits combining economic interactions, accounting systems, boundaries, and meaningful interactions among participants - circuits of commerce" (Zelizer 2007, 45). Isso implica que as pessoas participam de diferentes circuitos, simultaneamente, e também diferenciam os vários tipos de relações interpessoais, marcando-as com nomes distintos, símbolos, práticas e meios de troca diferentes. Para Zelizer (2005a), os agentes sempre têm certo cuidado para estabelecer limites entre as diferentes relações que surgem e mantêm através das negociações interpessoais. Nesse sentido, os limites variam e as pessoas estabelecem, negociam e reformulam as fronteiras de acordo com o grau de proximidade entre elas.

Segundo Bandelj (2012), esse significado, proposto por Zelizer, inclui o entendimento de quais símbolos, práticas e meios de troca são apropriados para diferentes tipos de relacionamento que as pessoas estabelecem na vida cotidiana. Esse processo é recíproco, mas convém destacar que "reciprocity doesn't mean equality" (Bandelj 2012. 180). Sendo assim, como bem pontua essa última autora, a negociação constante do conteúdo dos laços sociais não exclui o envolvimento em processos desiguais ou estratégias, que podem levar à desconfiança entre as partes.

Bandelj (2012) aponta que o foco no trabalho relacional afasta as análises das interpretações econômicas da ação racional, buscando superar o reducionismo estrutural e ampliar nossa visão ao enfatizar os fundamentos emocionais do intercâmbio, que por muito tempo foram negligenciados na Sociologia Econômica. Dessa forma, como demonstra a autora, ao preconizar que as pessoas estão constantemente negociando suas vidas sociais, a perspectiva relacional prioriza elementos da vida privada, como conexão, interdependência e coletividade, em contraste ao modelo econômico clássico, que privilegia características da esfera pública, como separação, individuação e independência.
Ossandón (2019), por sua vez, acredita que uma das maiores contribuições da noção de trabalho relacional é inaugurar uma nova forma de conceber a agência na Sociologia Econômica, pois os atores econômicos não devem apenas aprender a calcular, mas, sim, saber como distinguir e desembaraçar as regras simbólicas implicitas em casa transação.

Já Zelizer (2017a), afirma que o conceito de relational work aparece como algo que tem a capacidade de imprimir um rumo distinto ao conceito de embeddedness,4 "à vertente mais tradicional da Nova Sociologia Econômica, que, aliás, já está velha, mas que foi nova em algum momento" (Zelizer 2017a, 198). De acordo com a autora, os sociólogos que buscam uma Sociologia Econômica "alternativa" criticam a ideia de embeddedness ou imersão, pois, para eles, isso implica em considerar os processos sociais apenas como o "recipiente" da economia, "enquanto que o conteúdo permaneceria identificado por sistemas racionais de troca da economia standard" (Zelizer 2010, 380).

Atualmente, o uso do conceito de trabalho relacional aparece de maneira bastante ampliada, o que faz a autora afirmar que o mesmo "tem pernas próprias" (Zelizer 2017a, 198). Porém, na concepção de Zelizer, o conceito inclui o estabelecimento de laços sociais diferenciados, manutenção, remodelação, distinção de outras relações e até mesmo o próprio fim. Para a autora, os agentes sempre têm certo cuidado para estabelecer limites entre as diferentes relações que mantêm e que surgem através das negociações interpessoais. Dessa forma, a constante mistura entre vida privada e vida econômica faz com que as fronteiras entre as relações pessoais e profissionais sejam pouco delimitadas. Além disso, como demonstra Zelizer (2005), essas relações variam e as pessoas estabelecem, negociam e reformulam as fronteiras de acordo com o grau de proximidade com o qual estão vinculados (amigos, parentes, vizinhos), marcando e dando tratamento de maneira distinta, tanto às relações sociais como às formas de transferências monetárias. 


\section{Considerações finais}

A construção teórica de Viviana Zelizer inova ao propor uma abordagem sociológica que discute acerca da "pureza" e autenticidade das relações pessoais, que ressalta os valores culturais e sociais que formatam as relações econômicas. Se diferenciando das abordagens reducionistas, que separam o mercado e os sistemas impessoais de produção da solidariedade, da intimidade e da privacidade, o trabalho da autora tem sido o de demonstrar como os mercados são constantemente moldados pelos sistemas de significados, atribuídos pelas pessoas, e pelos contatos sociais que se estabelecem no intercurso da vida cotidiana.

Ao recusar as abordagens tradicionais da $\mathrm{Ci}$ ência Econômica, que reduzem e segmentam economia e intimidade, Zelizer oferece uma possibilidade de superar os antagonismos puristas que concebem o mercado, como uma esfera autônoma e isolada da vida social, mas, ao contrário, enxergando-o como algo que pressupõe e existe através de interações, de processos culturais, afetivos e de conexões interpessoais. O interesse maior está em perceber como todos esses fatores moldam a vida econômica e como os fatos econômicos acabam se "misturando" com as relações sociais dos agentes.

É seguindo essa linha que a autora demonstra a importância de criticar os esquemas teóricos convencionais e oferece uma abordagem sociológica não reducionista e não dicotômica dos vinculos entre intimidade, cultura e economia, suscitando, assim, uma análise otimista e questionadora das visões fatalistas que antagonizam o mercado e a vida emocional dos individuos, como se fossem realidades essencialmente contrárias e moralmente incompativeis.

Se, por um lado, as hipóteses dos mundos hostis consideram que a intimidade pode ser degradada pela monetarização, do outro, percebe-se que em muitas situações essa mistura não anula e nem corrompe as relações sociais, pois a ajuda, a solidariedade e a reciprocidade também podem se manter vivas e atuantes nesse processo. Ao superar a oposição entre intimidade e economia, a análise dos mundos conectados de
Zelizer nos oferece uma alternativa para pensar na vasta gama de possibilidades, que podem sugerir novos entendimentos sobre como a economia funciona, e, mais especificamente, sobre como podemos analisar a interseção entre relações econômicas e pessoais.

Por essa razão, assim como aponta Zelizer (2009), acredita-se que dicotomizar o social e o econômico obscurece a compreensão sobre como a vida econômica realmente opera, pois o processo de racionalização e de mercantilização do mundo nem sempre tem gerado como consequência efeitos homogeneizantes e corruptivos dos laços sociais. Dessa maneira, não podemos colocar como polos opostos e excludentes, as empresas e o mercado financeiro de um lado, e as abordagens sociais, culturais, sentimentais e intimas de outro. Ao invés de ver a interseção das esferas como algo que gera necessariamente conflito, confusão e corrupção, Zelizer nos ensina com maestria que é relevante estudar os conflitos e o que se passa nos entremeios das relações intimas, para entendermos como as pessoas conseguem integrar transferências monetárias, contratos e pagamentos, sem que isso necessariamente destrua os laços sociais envolvidos, pois normalmente o dinheiro coabita regularmente com a intimidade e até a sustenta.

As obras de Zelizer inspiram, portanto, a construção de um novo olhar sob a vida econômica e social, que leve em conta a conexão dos laços afetivos e as interações entre as pessoas, para que se possa entender o desenvolvimento dos mercados e a dinâmica das transações comerciais, contribuindo, assim, de modo inovador para os avanços da Sociologia Econômica. Todavia, tal como nos relembra Ossandón (2019), isso não implica dizer que as contribuições da autora sejam úteis para tudo, ou que devam substituir as abordagens já existentes, mas que o trabalho dela traz consigo importantes ganhos científicos e abre espaço para novas maneiras de conduzir pesquisas no campo da Economia e da Sociologia.

Por fim, como bem sugere Freire (2014, 260), Zelizer nos incita a "reinscrever o lugar dos afetos e das emoções no plano da análise sociológica", 
pois acredita-se que apenas análises criticas e alternativas dos processos econômicos e sociais poderão nos levar a trilhar novos caminhos.

\section{Referências}

Bandelj, Nina. 2012. "Relational work and Economic Sociology". Politics \& Society 40, 2: 175-201. https://doi. org/10.1177/0032329212441597

Ertman, Martha M. 2009. "For both love and money: Viviana Zelizer's The purchase of intimacy". Law \& Social Inquiry 4, 34:1017-1037. https://doi.org/10.1111/ j.1747-4469.2009.01173.x

Fernandes, Camila. 2013. "Zelizer, Viviana A. 2011. A negociação da intimidade". Mana 19, 2: 400-402. https:// doi.org/10.1590/S0104-93132013000200012

Freire, Alyson. 2014. "Economia versus intimidade: uma alternativa via as sociologias de Viviana Zelizer e Eva Illouz". Latitude 8, 2: 255-287. https://doi. org/10.28998/2179-5428.20140203

Granovetter, Mark. 2005. "The impact of social structure on economic". Journal of Economic Perspectives 19, 1:33-50. https://doi.org/10.1257/0895330053147958

Granovetter, Mark. 2007. "Ação econômica e estrutura social: o problema da imersão". Revista de Administração de Empresas 6, 1. https://doi.org/10.1590/S167656482007000100006

Guimarães, Nadya A.; André Vereta-Nahoum; Federico Neiburg e Bianca Freire-Medeiros. 2017. "A negociação da intimidade, dez anos depois. Entrevista com Viviana Zelizer". Tempo social 29, 1: 190-209. https://doi. org/10.11606/0103-2070.ts.2017.125519

Lopes Júnior, Edmilson. 2002. "As potencialidades analíticas da Nova Sociologia Econômica". Sociedade e Estado 17, 1: 39-62. https://doi.org/10.1590/S010269922002000100004

Ossandón, José. 2019. "Situating Zelizer: a beginners' guide". Sociologica 3, 13:185-190. https://doi. org/10.6092/issn.1971-8853/10131

Ossandón, José e Viviana Zelizer. 2019. "How did I become a historical economic sociologist? Viviana Zelizer in Conversation with José Ossandón". Sociologica 3, 13:191196. https://doi.org/10.6092/issn.1971-8853/10132

Steiner, Philippe. 2006. A Sociologia Econômica. São Paulo: Atlas.

Vale, Gláucia Maria Vasconcellos e Liliane de Oliveira Guimarães. 2010. "Redes sociais na criação e mortalidade de empresas". Revista de Administração de Empresas 50, 3: 325-337. https://doi.org/10.1590/ S0034-75902010000300008

Wilkinson, John. 2016. "Os mercados não vêm do "mercado"'. In Construção de mercados e agricultura familiar: desafios para o desenvolvimento rural, organizado por Flávia Charão Marques, Marcelo Antônio Conterato e Sergio Schneider, 53-74. Porto Alegre: Editora da Ufrgs.
Zelizer, Viviana. 2005a. "Circuits within capitalism". In The economic sociology of capitalism, organizado por Victor Nee e Richard Swedberg, 29-322. Princeton: Princeton University Press.

Zelizer, Viviana. 2005b. The purchase of intimacy. Princeton: Princeton University Press.

Zelizer, Viviana. 2007. "Viviana Zelizer answers ten questions about economic sociology". The European Electronic Newsletter 3, 8: 41-45. http://hdl.handle. net/10419/155894

Zelizer, Viviana. 2008. "Pasados y futuros de la sociología económica". Apuntes de investigación del Cecyp, 14. https://apuntescecyp.com.ar/index.php/apuntes/ article/view/125/110

Zelizer, Viviana. 2009. "Dualidades perigosas". Mana 15. 1: 237-256. https://doi.org/10.1590/S010493132009000100009

Zelizer, Viviana. 2010. "A economia do care". Civitas 10, 3: 376-391. https://doi.org/10.15448/19847289.2010 .3 .8337

Zelizer, Viviana. 2020. "Interview 15 Viviana A. Zelizer". In A Journey of Discovering Sociology. What sociology is in 20 contemporary American sociologists' eye, organizado por Long Chen, 145-155. Singapore: Springer. https:// doi.org/10.1007/978-981-15-6603-5_15

\section{Renata Bezerra Milanês}

Doutora e Mestra em Ciências Sociais em Desenvolvimento, Agricultura e Sociedade pela Universidade Federal Rural do Rio de Janeiro (UFRRJ), Rio de Janeiro, RJ, Brasil. Possui Bacharelado em Ciências Sociais pela Universidade Federal de Campina Grande (UFCG), Campina Grande, PB, Brasil.

Os textos deste artigo foram revisados por Zeppelini Publishers e submetidos para validação do(s) autor(es) antes da publicação. 